\title{
Marginal and internal fit of zirconia based fixed dental prostheses fabricated with different
} concepts

This article was published in the following Dove Press journal:

Clinical, Cosmetic and Investigational Dentistry

24 February 2010

Number of times this article has been viewed

\author{
Florian Beuer' \\ Natalie Korczynski' \\ Antonia Rezac' \\ Michael Naumann² \\ Wolfgang Gernet \\ John A Sorensen ${ }^{3}$ \\ 'Department of Prosthodontics, \\ Ludwig-Maximilians University, \\ Munich, Germany; ${ }^{2}$ Department of \\ Prosthodontics and Material Sciences, \\ University of Ulm, Germany; ${ }^{3}$ Pacific \\ Dental Institute, Portland, Oregon, \\ USA
}

Correspondence: Florian Beuer Department of Prosthodontics, LudwigMaximilians University, Goethestr. 70, 80336 Munich, Germany

Tel +498951609514

$\mathrm{Fax}+498951609502$

Email florian.beuer@med.uni-muenchen.de
Abstract: The purpose of this in vitro study was to compare the precision of fit of substructures milled from semi-sintered zirconia blocks, fabricated with two different fabrication concepts. Three-unit, posterior fixed dental prostheses (FDP) were fabricated for standardized dies ( $\mathrm{n}=10)$ with the laboratory Computer Aided Design (CAD)/Computer Aided Manufacturing (CAM) system Cercon ${ }^{\circledR}$ Brain (Brain) and the centralized CAD/CAM system Compartis Integrated Systems (Compartis). After cementation to the dies, the FDP were embedded and sectioned. Four cross-sections were made of each abutment tooth, and marginal and internal fit were evaluated under an optical microscope. A one-way analysis of variance (ANOVA) was used to compare data ( $\alpha=0.05$ ). Mean gap dimensions at the marginal opening for Brain and Compartis were 56.0 $( \pm 34.5) \mu \mathrm{m}$ and $51.7( \pm 45.2) \mu \mathrm{m}$, respectively. Mean internal gap dimensions of $62.8( \pm 37.5) \mu \mathrm{m}$ to $164.6( \pm 33.4) \mu \mathrm{m}$ were measured depending on the measurement location and the fabrication concept. Mean marginal openings and internal adaptations were not significantly different for both systems. Three out of four measurement locations showed significantly different cement gaps. Within the limitations of this study, the results suggest that the accuracy of both investigated systems is satisfactory for clinical use. The laboratory fabrication exhibited similar accuracy as the centralized manufacturing.

Keywords: zirconia, CAD/CAM, fit, FDP, all-ceramic

\section{Introduction}

In attempts to improve the strength and fracture toughness of dental prostheses, several new ceramic materials and techniques have been developed during the last decades. All-ceramic fixed dental prostheses (FDP) frameworks can be made from various high-strength ceramic materials. ${ }^{1}$ Yttria-stabilized zirconia has proven clinical suitability for posterior FDP. ${ }^{1-3}$

Similar to metal-ceramics, the fabrication of zirconia based FDP uses a highstrength ceramic material for the framework, to provide resistance against cyclic loading. ${ }^{1-3}$

Computer aided manufacturing (CAM) of zirconia substructures currently utilizes two different strategies for the type of milling blocks used. The hardness of the zirconia blocks and hence the difficulty in milling the substructures is determined by the degree of sintering of the blocks. Originally, blocks were fully sintered by a process known as hot isostatic pressing (HIP). Milling the actual size of the substructure is associated with disadvantages, such as high wear rates of the milling burs in the CAM machines and prolonged milling time due to slower feed. ${ }^{4,5}$ Since there is no further sintering necessary and therefore no sintering shrinkage, the marginal fit of these substructures is 
excellent. ${ }^{4,5}$ The demonstrated marginal values for this technique are 60.4 and $74.0 \mu \mathrm{m} .{ }^{4}$ Another study showed that high precision can be achieved using milling devices for densely sintered zirconia. ${ }^{6}$ A second method of milling block fabrication utilizes a semi-sintered zirconia material. The semisintered block has a chalk-like consistency, making it easily machineable in the CAM unit. After milling, the substructure is then sintered to full density. The post-milling sintering results in a linear shrinkage in the range of $15 \%$ to $30 \%$ and subsequent increase in density. ${ }^{2,7}$ The increased milling efficiency of the softer semi-sintered block has the trade-off of a potential poorer fit from a $20 \%$ sintering shrinkage, the scanning process, compensatory software design and milling. Apart from the mechanical properties and esthetics, the longterm clinical success of all-ceramic fixed prosthodontics can be influenced significantly by marginal discrepancies. Poor marginal adaptation increases plaque retention and changes the distribution of the microflora, which can induce the onset of periodontal disease. ${ }^{2,7-10}$ Microleakage from the oral cavity can cause endodontic inflammation. ${ }^{8}$ A clinical study on a CAM only system (DCM prototype of Cercon, DeguDent, Hanau, Germany) reported poor marginal fit and a 22\% rate of secondary caries after 5 years. ${ }^{2}$ Currently chipping of the veneering porcelain appears to be one of the major drawbacks of zirconia-based restorations. ${ }^{2,11-15}$ There is evidence available demonstrating the influence of excessive cement space on failure of the veneering porcelain. ${ }^{16}$ This thick cement layer complicates the challenge to minimize stress concentrations on the tensile surface of the restoration caused by the viscoplastic deformation of the adhesive material und cyclic loading. It was reported that currently recommended cements flow under load. ${ }^{17-19}$ This flow increases the stress in the system consisting of substructure and veneering porcelain dramatically. ${ }^{16,20,21}$ The increased stress propagates damage and may cause failure of the veneering porcelain. ${ }^{16}$

There is consensus between various authors that marginal openings below $120 \mu \mathrm{m}$ are clinically acceptable. ${ }^{22-25}$ Numerous studies have examined the marginal fit of porcelain crowns, ${ }^{4,6,8,26-34}$ however, in vitro measurement data for the marginal fit of Compartis Integrated Systems CAD/CAMsystem have not been reported. There is evidence that centralized fabrication of zirconia substructures is superior to laboratory systems regarding accuracy. ${ }^{33}$ However, this study investigated three completely different CAD/CAMsystems. ${ }^{33}$ The CAD/CAM system used in this study offers 2 options of fabrication: The coping can be fabricated in the dental laboratory (Cercon Brain, DeguDent) or in the milling center (Compartis Integrated Systems, DeguDent). While the same scanning unit, software and porous zirconia are used the CAM-milling machines are different. ${ }^{35}$ It might be questioned if the place of fabrication influences the precision of the prosthesis.

Therefore the purpose of this investigation was to measure the marginal opening and internal adaptation of zirconiabased restorations to the working dies manufactured by the same CAD/CAM-system with exception of the milling unit. The working hypothesis states that; (1) both systems produce marginal openings below $120 \mu \mathrm{m}$ and that (2) the centralized $\mathrm{CAD} / \mathrm{CAM}$ system improves the marginal and internal fits that laboratory CAD/CAM system.

\section{Materials and methods Die fabrication}

A typodont model (Frasaco, Tettnang, Germany) with a missing mandibular right first molar was used. A $1.2 \mathrm{~mm}$, 360 -degree chamfer preparation was made on the second premolar and second molar. To control axial reduction, a silicone impression (Optosil ${ }^{\circledR}$, Heraeus Kulzer, Hanau, Germany) was made prior to tooth preparation. Additionally, the provisional crown (Protemp $3^{\mathrm{TM}}$ Garant, $3 \mathrm{M}^{\mathrm{TM}}$ ESPE) was used to verify the thickness, so the circumferential and occlusal reduction could be quantified (Dial Caliper, Kori Seiki, Tokyo, Japan). The preparation was completed with a surveyor (F1, DeguDent) using a carbide bur (Komet $\mathrm{H}$ 356 RGE 103.031, Brasseler GmbH, Lemgo, Germany) to ensure that the preparation had a total taper of 8-degree. Twenty polyether impressions (Impregum ${ }^{\mathrm{TM}}, 3 \mathrm{M}^{\mathrm{TM}}$ ESPE) were made with a metal impression tray (U3 \# 141163 Orbilock $^{\circledR}$, Orbis Dental, Münster, Germany) and poured in a class IV resin-reinforced (ISO type IV) die stone (ResinRock, Whip Mix Europe, Dortmund, Germany). After the dies set, pins (Pindex System, Coltene Whaledent, Altstätten, Switzerland) were placed in the appropriate locations, and the base of the cast was poured in the same dental stone. Dies were removed from cast base, and trimmed to the preparation margins. The same investigator made all impressions, and all dies were fabricated by the same experienced technician. Twenty definitive casts with removable dies were fabricated and divided into two groups. The precision of fit of the substructure was measured without veneering. ${ }^{8,36}$ The definitive dies were sent to a dental laboratory.

\section{Laboratory CAD/CAM system}

The digitalization of the dies was performed by a laser scanner (Cercon eye, DeguDent ${ }^{\circledR}$, Hanau, Germany) and the substructures were designed on the CAD program of the 
system (Cercon art, DeguDent ${ }^{\circledR}$ ). The construction of the retainers was carried out with a standardized protocol. The settings were: a wall thickness of $0.4 \mathrm{~mm}$ and a virtual cement layer of $20 \mu \mathrm{m}$ starting $1 \mathrm{~mm}$ above the margin.

Ten zirconia retainers were fabricated at the laboratory of Munich dental school using the laboratory CAM unit of the system (Cercon Brain). The data were enlarged by $30 \%$ and the frameworks were milled from semi-sintered zirconia blanks (Cercon base $30 \mathrm{~mm}$, DeguDent ${ }^{\circledR}$ ). The milled, enlarged frameworks were sintered to full density at a temperature of $1623 \mathrm{~K}$ resulting in shrinkage to the desired dimensions.

\section{Milling center CAD/CAM system}

Ten zirconia frameworks were fabricated by a milling center (Compartis Integrated Systems). The data of the designed substructures were sent via Internet to the milling center and the sintered substructures were sent back after 48 hours.

All frameworks were examined for deformity and debris, and steam-cleaned (Triton SLA, Bego, Bremen, Germany). All frameworks were returned to their respective dies and controlled in terms of seating. In case of incomplete seating, an additional adaptation of the framework was performed using a standardized protocol according to the literature and clinical practice. ${ }^{11,33,37-39}$ To identify areas that needed correction, lipstick (Shine Délicieux, L’Oréal, Paris, France) was applied to the master cast, and the framework was placed without force. The red spots inside the framework were removed using a redring diamond ball instrument (Komet 8801.016, Brasseler) with water-cooling spray. This procedure was repeated until the marked indicator spots disappeared and a uniform and even contact of the coping on the die was achieved. After each refinement the color was removed from the die by a steam cleaner. The same experienced dental technician adapted and checked all the restorations. After the adaptation process the supervising dentist controlled the seating. The examiner inter-agreement factor was $95 \%$.

\section{Cementation process}

Additionally all retainers were cemented on the definitive dies by glass ionomer (KetacCem Aplicap, 3M ESPE). ${ }^{40,41}$ The capsule of glass ionomer cement was activated for

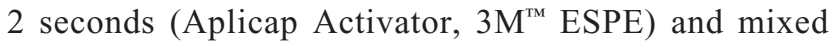
automatically (Rotomix, $3 \mathrm{M}^{\mathrm{TM}}$ ESPE) for 10 seconds. The abutments of the retainers were filled (Aplicap Applier, $3 \mathrm{M}^{\mathrm{TM}}$ ESPE) with cement, and the cement was spaced out by a disposable brush until the complete surface was coated.
The retainer was set back onto the definitive die with finger pressure, and the excess cement was removed. A special cementing device was used to ensure that the pontic was loaded centrally at a force of $50 \mathrm{~N}$ for 10 minutes. ${ }^{42}$ The same team of an experienced dentist, who sat the retainer onto the dies, and a dental assistant, who activated the capsule of cement and started the mixing procedure, cemented all substructures. The middles of both abutment teeth were marked on the die in order to have standardized sectioning. Twenty-four hours after cementation, every framework was embedded into gypsum (ResinRock, Whip Mix, Louisville, $\mathrm{KY}$, USA) to prevent raptures and disruptions and crosssectioned (Accutom 2, Struers, Willich, Germany). The pontic was discarded, and the abutment teeth were sectioned centrally from buccal to lingual and from mesial to distal according to the pencil-lines at the middles of both abutment teeth, thus resulting in 8 specimens to be evaluated for each framework.

\section{Fit evaluation}

The measurement procedure was described in prior studies. ${ }^{33,34}$ For each substructure, the following four measurement locations were used to determine the precision of fit between the retainers and the dies:

1. Marginal Opening (MO): The marginal opening at the point of closest approximation between the die and ceramic margin of the retainer.

2. Chamfer Area (CA): The internal adaptation of the retainer at the point of the biggest diameter.

3. Axial Wall (AW): The internal adaptation of the crown walls at the midpoint of the axial wall (2 $\mathrm{mm}$ occlusal to the margin of the die).

4. Occlusal Adaptation (OA): The internal adaptation of the surface of the crown to the die at the midpoint from the facial and proximal.

The fit of the substructures was evaluated using the scan line schema (Figure 1) planned for the investigation, measurements were taken from the database at MO, CA, $\mathrm{AW}$ and $\mathrm{OA}$ measurement locations to evaluate the fit of all retainers. Data recorded at the different cross-sections of one specimen were averaged by the different measurement locations.

\section{Statistical analysis}

Data were imported in a statistical program (SPSS 16.0, SPSS Germany, Munich, Germany). Mean data were calculated and analyzed with descriptive statistics. A one-way analysis 


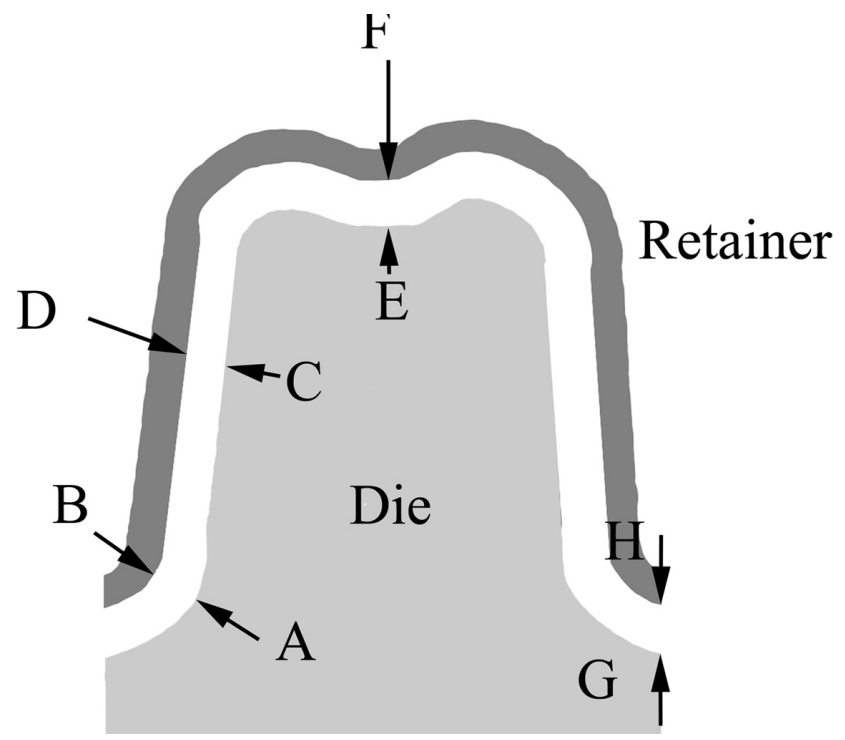

Figure I Crown to die diagram showing measurement locations to determine marginal opening (MO; distance between $A$ and $B$ ), chamfer area (CA; distance between $C$ and $D$ ), axial wall ( $A W$; distance between $F$ and $E$ ) and occlusal adaptation (OA; distance between $\mathrm{G}$ and $\mathrm{H}$ ).

of variance (ANOVA) was carried out to detect statistical difference between both investigated systems in terms of marginal fit and internal fit at the different measurement locations. To show the difference between the measurement locations a one-way ANOVA and a post hoc test (Student-NewmanKeuls) was used. The level of significance was set at $5 \%$.

\section{Results}

The mean Marginal gap dimension for Brain and Compartis were $56.0( \pm 34.5) \mu \mathrm{m}$ and $51.7( \pm 45.2) \mu \mathrm{m}$, respectively. The mean internal adaptation gap dimensions for Brain were $100.3( \pm 42.7) \mu \mathrm{m}(\mathrm{CA}), 67.3( \pm 52.6) \mu \mathrm{m}(\mathrm{AW})$, and 161.2 ( \pm 119.7$) \mu \mathrm{m}(\mathrm{OA})$. Compartis showed mean internal adaptation gap dimensions of $99.7( \pm 32.4) \mu \mathrm{m}(\mathrm{CA}), 62.8$ $( \pm 37.5) \mu \mathrm{m}(\mathrm{AW})$, and $164.6( \pm 33.4) \mu \mathrm{m}(\mathrm{OA})$ (Figure 2).

Table 1 presents the one-way ANOVA on the system groups by $\mathrm{MO}, \mathrm{CA}, \mathrm{AW}$ and $\mathrm{OA}$ measurement locations.

Table I One-wayANOVAs of between-system factor by measurement locations (MO, CA, AW and OA)

\begin{tabular}{llllll}
\hline Source & df & $\begin{array}{l}\text { Sum of } \\
\text { squares }\end{array}$ & $\begin{array}{l}\text { Mean } \\
\text { squares }\end{array}$ & F value & $P$ value \\
\hline MO & I & 17.047 & 17.047 & 0.012 & 0.915 \\
CA & I & 866.673 & 866.673 & 0.410 & 0.523 \\
AW & I & 245.205 & 245.205 & 0.028 & 0.867 \\
OA & I & 757.985 & 757.985 & 0.468 & 0.495 \\
\hline
\end{tabular}

a $P=0.05$.

Abbreviations: df, degrees of freedom; MO, marginal opening; CA, chamfer area. AW, axial wall; OA, occlusal adaptation.

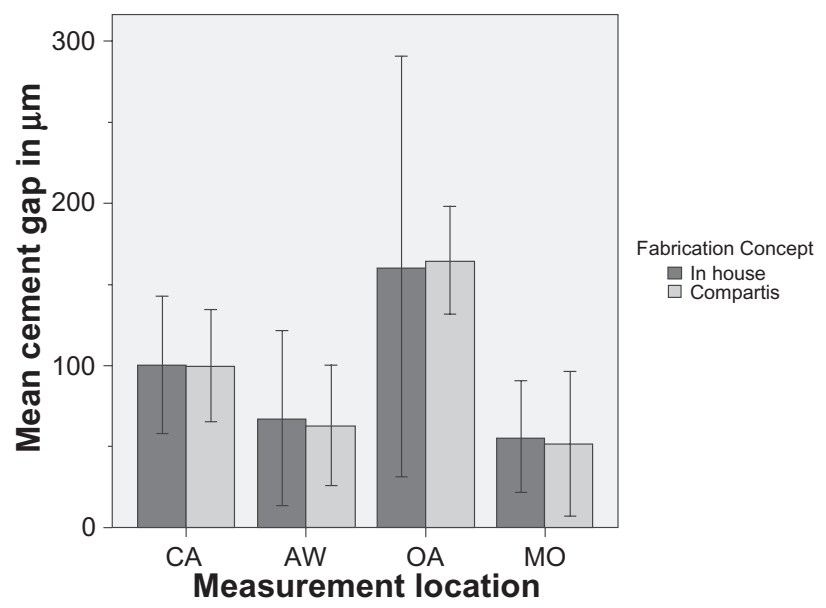

Figure 2 Mean gap dimension and standard deviation at marginal opening (MO), chamfer area (CA), axial wall (AW) and occlusal adaptation (OA) measurement locations for both investigated systems.

Mean gap dimensions between the system groups were significantly different at $\mathrm{MO}, \mathrm{CA}$ and $\mathrm{OA}$. The measurement location AW did not demonstrate any significant differences between both systems. The measurement locations showed significantly different values, while 4 homogeneous groups were detected (Tables 2 and 3 ).

\section{Discussion}

An acceptable Marginal gap for full crowns, as reported by Hung and colleagues, is 50 to $75 \mu \mathrm{m},{ }^{30}$ whereas Weaver and colleagues suggested $70( \pm 10) \mu \mathrm{m} .{ }^{28}$ The mean marginal openings for both investigated systems were $56.0 \mu \mathrm{m}$ (Brain) and $51.7 \mu \mathrm{m}$ (Compartis), respectively. Both systems showed comparable MO to other investigated all-ceramic systems, ${ }^{6-9,31,43}$ which means that the part of the working hypothesis concerning marginal fit, that would be clinically acceptable, can be supported.

It has to be taken in account that in vitro studies offer standardized and optimized conditions in terms of the preparation design, impression technique or experimental performance. Therefore, the results of the present study show the precision of $\mathrm{CAD} / \mathrm{CAM}$ systems under ideal conditions. A clinical evaluation of the Lava system reported a mean $\mathrm{MO}$

Table 2 One-way ANOVA on the measurement location factor (MO, CA, AW, and OA)

\begin{tabular}{llllll}
\hline Source & df & $\begin{array}{l}\text { Sum of } \\
\text { squares }\end{array}$ & $\begin{array}{l}\text { Mean } \\
\text { squares }\end{array}$ & F value & P value \\
\hline Complete data & 3 & 779459.363 & 259819.788 & 96.154 & $0.000^{\mathrm{a}}$ \\
\hline
\end{tabular}

ap $=0.05$.

Abbreviations: $\mathrm{df}$, degrees of freedom; MO, marginal opening; CA, chamfer area; $\mathrm{AW}$, axial wall; $\mathrm{OA}$, occlusal adaptation. 
Table 3 Student-Newman-Keuls post hoc test on different measurement locations.

\begin{tabular}{ll}
\hline Measurement location & Subgroup I \\
\hline MO & $53.7 \mu \mathrm{m}^{\mathrm{a}}$ \\
$\mathrm{AW}$ & $64.0 \mu \mathrm{m}^{\mathrm{a}}$ \\
$\mathrm{CA}$ & $100.0 \mu \mathrm{m}^{\mathrm{b}}$ \\
$\mathrm{OA}$ & $163.0 \mu \mathrm{m}^{\mathrm{c}}$ \\
\hline
\end{tabular}

Notes: Different superscript letters indicate statistic difference of the presented groups.

Abbreviations: $M O$, marginal opening; $C A$, chamfer area; $A W$, axial wall; $O A$, occlusal adaptation.

of $80( \pm 50) \mu \mathrm{m}$, which included inaccuracies caused by the $\mathrm{CAD} / \mathrm{CAM}$ system and the clinical procedure. ${ }^{7}$ Measurements on Procera crowns in vivo exhibited gap widths that were 61 to $70 \mu \mathrm{m}$ wider in bucco-lingual direction and 58 to $73 \mu \mathrm{m}$ wider in proximal locations than gap widths measured in vitro. ${ }^{32}$ According to May and colleagues. the $\mathrm{MO}$ was defined as the closest distance between retainer and preparation to avoid that overextension or underextension of the retainer crown could affect the result. ${ }^{10,43}$ The cement space or internal adaptation is considered to be a uniform space that facilitates seating without compromising retention and resistance forms. This is of paramount importance because all-ceramic restorations are more fragile compared to metal-ceramics, as ceramic is a brittle material and sensitive to tension. The precision of fit can influence the clinical prognosis. Tuntiprawon and Wilson reported that all-ceramic crowns displayed greater compressive strength when the mean AW was at a gap dimension of $73 \mu \mathrm{m} .{ }^{27}$ Their study also showed that if the mean AW was increased to $122 \mu \mathrm{m}$, lower fracture strength occurred without any significant improvement in seating. ${ }^{27}$ Both investigated CAD/CAM systems could fulfill this requirement. The obtained data did not indicate that there were incidences of axial wall contact between dies and the retainers, which would have been visible in the cross-sections.

As reported in a clinical investigation widest gap dimensions were found in OA. ${ }^{7}$ Thin cement layers $(80 \mu \mathrm{m})$ at measurement location OA have been reported to be more favorable for the mechanical stability of zirconia based restorations. ${ }^{21}$ There is also evidence that a lack of precision in internal fit can promote higher risks for veneering fracture. ${ }^{20}$ Apart from mechanical properties of the material used, this also has a clinical aspect. If too much space is lost as a result of large interocclusal discrepancies, the intercuspal clearance available for veneering is reduced. Despite this aspect, the result of the present study indicates that gaps were similar or better to those of metal ceramic restorations. ${ }^{26,29}$
Based on the literature there is evidence that the fabrication concept has a major impact on the fit. Centralized fabrication performed significantly better compared to a laboratory $\mathrm{CAD} / \mathrm{CAM}$ system and a laboratory CAM system. ${ }^{33}$ However, the systems tested in that study used different scanning devices, different CAD-software and different semi-sintered zirconia. ${ }^{33}$ No difference in accuracy between both fabrication concepts could be detected rejecting the second part of the working hypothesis. When the same preparation model, scanning device, CAD-software, semisintered zirconia material and sintering device are used the milling machine seems to have no influence on the fit.

The limitations of the present study were: (1) All frameworks were adapted, to avoid inaccuracies a standardized protocol was used. The same technician adapted all substructures and at least two calibrated examiners verified as being the best possible fit in their opinion. This influence can therefore be considered the minimal unavoidable degree of error inherent to the system. This procedure also reflects the manufacturing process in the dental laboratory. (2) The gap dimensions were measured using the cross-section technique. As a result the precision was just measured at 8 defined areas per retainer, which might not represent the complete fit. Cross sectioning might also cause damage to the specimens. Therefore all specimens were embedded in gypsum, crosssectioned under water spray and low feeding rates to avoid possible inaccuracies through damaged specimens. (3) All retainers were cemented onto their respective dies. Therefore the marginal fit could have been influenced by this procedure. However, as the used cement requires a space of $20 \mu \mathrm{m}$, it is theorized that the luting space measured and represented by the cement width did not prevent the accurate seating of the retainers as a result of hydraulic pressure. (4) All retainers were produced and tested under ideal conditions, which might not reflect the precision in daily clinical use. Further research should be carried out testing different spans of FDP and more available systems (CAM-technology, handcopying-technology).

\section{Conclusions}

According to the results of this study the following conclusions can be drawn:

1. Both milling concepts tested demonstrated in-vitro acceptable marginal openings.

2. The differences of fit depended on the region of the retainer being evaluated.

3. Laboratory milling of semi-sintered zirconia exhibited similar accuracy as centralized milled zirconia substructures. 


\section{Acknowledgements}

DeguDent supported this study with materials. The authors would like to thank the laboratory staff of the prosthodontic department of Munich Dental School for their support. The authors would like to thank Dr. Kurt Erdelt for his assistance with the statistical analysis and the computer measurement.

\section{Disclosures}

The authors report no conflicts of interest in this work.

\section{References}

1. Tinscher J, Natt G, Mohrbotter N, Spiekermann H, Schulze KA. Lifetime of alumina- and zirconia ceramics used for crown and bridge restorations. J Biomed Mater Res B Appl Biomater. 2007;80(2):317-321.

2. Sailer I, Fehér A, Filser F, Gauckler LJ, Lüthy H, Hämmerle CH. Five-year clinical results of zirconia frameworks for posterior fixed partial dentures. Int J Prosthodont. 2007;20(4):383-388.

3. Tinschert J, Natt G, Mautsch W, Augthun M, Spiekermann H. Fracture resistance of lithium disilicate-, alumina-, and zirconia-based three-unit fixed partial dentures: a laboratory study. Int J Prosthodont. 2001;14(3):231-238.

4. Tinschert J, Natt G, Mautsch W, Spiekermann H, Anusavice KJ. Marginal fit of alumina-and zirconia-based fixed partial dentures produced by a CAD/CAM system. Oper Dent. 2001;26(4):367-374.

5. Vult von Steyern P, Carlson P, Nilner K. All-ceramic fixed partial dentures designed according to the DC-Zirkon technique. A 2-year clinical study. J Oral Rehabil. 2005;32(3):180-187.

6. Coli P, Karlsson S. Precision of a CAD/CAM technique for the production of zirconium dioxide copings. Int J Prosthodont. 2004;17(5):577-580.

7. Reich S, Wichmann M, Nkenke E, Proeschel P. Clinical fit of all-ceramic three-unit fixed partial dentures, generated with three different CAD/ CAM systems. Eur J Oral Sci. 2005;113(2):174-179.

8. Bindl A, Mormann WH. Marginal and internal fit of all-ceramic CAD/CAM crown-copings on chamfer preparations. J Oral Rehabil. 2005;32(6):441-447.

9. Schaerer P, Sato T, Wohlwend A. A comparison of the marginal fit of three cast ceramic crown systems. J Prosthet Dent. 1988;59(5):534-542.

10. Holmes JR, Bayne SC, Holland GA, Sulik WD. Considerations in measurement of marginal fit. J Prosthet Dent. 1989;62(4):405-408.

11. Beuer F, Schweiger J, Eichberger M, Kappert HF, Gernet W, Edelhoff D. High-strength $\mathrm{CAD} / \mathrm{CAM}$-fabricated veneering material sintered to zirconia copings-A new fabrication mode for all-ceramic restorations. Dent Mater. 2009;25(1):121-128.

12. Edelhoff D, Florian B, Florian W, Johnen C. HIP zirconia fixed partial dentures-clinical results after 3 years of clinical service. Quintessence Int. 2008;39(6):459-471.

13. Molin MK, Karlsson SL. Five-year clinical prospective evaluation of zirconia-based Denzir 3-unit FPDs. Int J Prosthodont. 2008; 21(3):223-227.

14. Rosentritt M, Behr M, Thaller C, Rudolph H, Feilzer A. Fracture performance of computer-aided manufactured zirconia and alloy crowns. Quintessence Int. 2009;40(8):655-662.

15. Tinschert J, Schulze KA, Natt G, Latzke P, Heussen N, Spiekermann H. Clinical behavior of zirconia-based fixed partial dentures made of DC-Zirkon: 3-year results. Int J Prosthodont. 2008; 21(3):217-222.

16. Rekow ED, Zhang G, Thompson V, Kim JW, Coehlo P, Zhang Y. Effects of geometry on fracture initiation and propagation in all-ceramic crowns. J Biomed Mater Res B Appl Biomater. 2009;88(2)436-446.
17. Hirano S, Hirasawa T. Compressive creep of posterior and anterior composite resins in water. Dent Mater J. 1994;13(2):214-219.

18. Vaidyanathan J, Vaidyanathan TK. Flexural creep deformation and recovery in dental composites. J Dent. 2001;29(8):545-551.

19. Ferracane JL, Matsumoto H, Okabe T. Time-dependent deformation of composite resins - compositional considerations. J Dent Res. 1985;64(11):1332-1336.

20. Rekow D, Thompson VP. Near-surface damage - a persistent problem in crowns obtained by computer-aided design and manufacturing. Proc Inst Mech Eng [H]. 2005;219(4):233-243.

21. Rekow ED, Harsono M, Janal M, Thompson VP, Zhang G. Factorial analysis of variables influencing stress in all-ceramic crowns. Dent Mater. 2006;22(2):125-132.

22. Belser UC, MacEntee MI, Richter WA. Fit of three porcelain-fused-tometal marginal designs in vivo: a scanning electron microscope study. J Prosthet Dent. 1985;53(1):24-29.

23. Karlsson S. The fit of Procera titanium crowns. An in vitro and clinical study. Acta Odontol Scand. 1993;51(3):129-134.

24. McLean JW, von Fraunhofer JA. The estimation of cement film thickness by an in vivo technique. Br Dent $J$. 1971;131(3):107-111.

25. Sulaiman F, Chai J, Jameson LM, Wozniak WT. A comparison of the marginal fit of In-Ceram, IPS Empress, and Procera crowns. Int $J$ Prosthodont. 1997;10(5):478-484.

26. Sorensen JA, Okamoto SK, Seghi RR, Yarovesky U. Marginal fidelity of four methods of swaged metal matrix crown fabrication. $J$ Prosthet Dent. 1992;67(2):162-173.

27. Tuntiprawon M, Wilson PR. The effect of cement thickness on the fracture strength of all-ceramic crowns. Aust Dent J. 1995; 40(1):17-21.

28. Weaver JD, Johnson GH, Bales DJ. Marginal adaptation of castable ceramic crowns. J Prosthet Dent. 1991;66(6):747-753.

29. Grey NJ, Piddock V, Wilson MA. In vitro comparison of conventional crowns and a new all-ceramic system. $J$ Dent. 1993;21(1):47-51.

30. Hung SH, Hung KS, Eick JD, Chappell RP. Marginal fit of porcelain-fused-to-metal and two types of ceramic crown. J Prosthet Dent. 1990;63(1):26-31.

31. Fleming GJ, Dobinson MM, Landini G, Harris JJ. An in-vitro investigation of the accuracy of fit of Procera and Empress crowns. Eur J Prosthodont Restor Dent. 2005;13(3):109-114.

32. Kokubo Y, Ohkubo C, Tsumita M, Miyashita A, Vult von Steyern P, Fukushima S. Clinical marginal and internal gaps of Procera AllCeram crowns. J Oral Rehabil. 2005;32(7):526-530.

33. Beuer F, Aggstaller H, Edelhoff D, Gernet W, Sorensen J. Marginal and internal fits of fixed dental prostheses zirconia retainers. Dent Mater. 2009;25(1):94-102.

34. Beuer F, Neumeier P, Naumann M. Marginal fit of 14-unit zirconia fixed dental prosthesis retainers. J Oral Rehabil. 2009;36(2)142-149.

35. Beuer F, Schweiger J, Edelhoff D. Digital dentistry: an overview of recent developments for CAD/CAM generated restorations. Br Dent J. 2008;204(9):505-11.

36. Bindl A, Mormann WH. Fit of all-ceramic posterior fixed partial denture frameworks in vitro. Int $J$ Periodontics Restorative Dent. 2007;27(6):567-575.

37. Witkowski S, Komine F, Gerds T. Marginal accuracy of titanium copings fabricated by casting and $\mathrm{CAD} / \mathrm{CAM}$ techniques. J Prosthet Dent. 2006;96(1):47-52.

38. Beuer F, Aggstaller H, Edelhoff D, Gernet W. Effect of Preparation Design on the Fracture Resistance of Zirconia Crown Copings. Dent Mater J. 2008;27(3):362-367.

39. Beuer F, Beuer F, Edelhoff D, Gernet W, Sorensen JA. Three-year clinical prospective evaluation of zirconia-based posterior fixed dental prostheses (FDPs). Clin Oral Investig. 2009;13(4)445-451.

40. Ozcan M, Kerkdijk S, Valandro LF. Comparison of resin cement adhesion to Y-TZP ceramic following manufacturers' instructions of the cements only. Clin Oral Investig. 2008;12(3)279-282.

41. Pospiech P. All-ceramic crowns: bonding or cementing? Clin Oral Investig. 2002;6(4):189-197. 
42. Proussaefs P. Crowns cemented on crown preparations lacking geometric resistance form. Part II: effect of cement. J Prosthodont 2004;13(1):36-41.
43. May KB, Russell MM, Razzoog ME, Lang BR. Precision of fit: the Procera AllCeram crown. J Prosthet Dent. 1998;80(4):394-404.

\section{Publish your work in this journal}

Clinical, Cosmetic and Investigational Dentistry is an international, peer-reviewed, open access, online journal focusing on the latest clinical and experimental research in dentistry with specific emphasis on cosmetic interventions. Innovative developments in dental materials, techniques and devices that improve outcomes and patient satisfaction and preference will be highlighted. The manuscript management system is completely online and includes a very quick and fair peer-review system, which is all easy to use. Visit http://www.dovepress.com/testimonials.php to read real quotes from published authors.

Submit your manuscript here: http://www.dovepress.com/clinical-cosmetic-and-investigational-dentistry-journal 